\title{
Characterization and expression analysis of a newly identified glutathione S-transferase of the hard tick Haemaphysalis longicornis during blood-feeding
}

Emmanuel Pacia Hernandez ${ }^{1,2}$, Kodai Kusakisako ${ }^{1,2}$, Melbourne Rio Talactac $^{1,2,3}$, Remil Linggatong Galay ${ }^{4}$, Takeshi Hatta ${ }^{5}$, Tomohide Matsuo ${ }^{2,6}$, Kozo Fujisaki $^{7}$, Naotoshi Tsuji ${ }^{5}$ and Tetsuya Tanaka ${ }^{1,2^{*}}$

\begin{abstract}
Background: Ticks are obligate hematophagous parasites important economically and to health. Ticks consume large amounts of blood for their survival and reproduction; however, large amounts of iron in blood could lead to oxidative stress. Ticks use several molecules such as glutathione S-transferases (GSTs), ferritins, and peroxiredoxins to cope with oxidative stress. This study aimed to identify and characterize the GSTs of the hard tick Haemaphysalis longicornis in order to determine if they have a role in coping with oxidative stress.

Methods: Genes encoding GSTs of H. Iongicornis were isolated from the midgut CDNA library. Genes have been cloned and recombinant GSTs have been expressed. The enzymatic activities, enzyme kinetic constants, and optimal pH of the recombinant GSTs toward 1-chloro-2,4-dinitrobenzene (CDNB) were determined. The gene transcription and protein expression profiles were determined in the whole ticks and internal organs, and developmental stages using real time RT-PCR and Western blotting during blood feeding. The localization of GST proteins in organs was also observed using immunofluorescent antibody test (IFAT).

Results: We have isolated two genes encoding GSTs (HIGST and HIGST2). The enzymatic activity toward CDNB is 9. $75 \pm 3.04$ units/mg protein for recombinant HIGST and $11.63 \pm 4.08$ units/mg protein for recombinant HIGST2. Kinetic analysis of recombinant HIGST showed $K_{m}$ values of $0.82 \pm 0.14 \mathrm{mM}$ and $0.64 \pm 0.32 \mathrm{mM}$ for the function of CDNB and GSH, respectively. Meanwhile, recombinant HIGST2 has $K_{m}$ values of $0.61 \pm 0.20 \mathrm{mM}$ and $0.53 \pm 0.02 \mathrm{mM}$ for the function of CDNB and GSH, respectively. The optimum pH of recombinant HIGST and recombinant HIGST2 activity was 7.5-8.0. Transcription of both GSTs increases in different developmental stages and organs during blood-feeding. GST proteins are upregulated during blood-feeding but decreased upon engorgement in whole ticks and in some organs, such as the midgut and hemocytes. Interestingly, salivary glands, ovaries, and fat bodies showed decreasing protein expression during blood-feeding to engorgement. Varying localization of GSTs in the midgut, salivary glands, fat bodies, ovaries, and hemocytes was observed depending on the feeding state, especially in the midgut and salivary glands.

(Continued on next page)
\end{abstract}

\footnotetext{
* Correspondence: k6199431@kadai.jp

'Laboratory of Infectious Diseases, Joint Faculty of Veterinary Medicine,

Kagoshima University, 1-21-24 Korimoto, Kagoshima 890-0056, Japan

${ }^{2}$ Department of Pathological and Preventive Veterinary Science, The United

Graduate School of Veterinary Science, Yamaguchi University, Yoshida,

Yamaguchi 753-8515, Japan

Full list of author information is available at the end of the article
} 
(Continued from previous page)

Conclusions: In summary, a novel GST of H. longicornis has been identified. Characterization of the GSTs showed that GSTs have positive correlation with the degree and localization of oxidative stress during blood-feeding. This could indicate their protective role during oxidative stress.

Keywords: Glutathione S-transferases, Haemaphysalis longicornis, Tick, Oxidative stress, Blood-feeding

\section{Background}

Ticks are obligate hematophagous parasites prevalent worldwide. They serve as several disease vectors in humans and other animals [1]. Haemaphysalis longicornis is a tick with a distribution in Australia, New Zealand and eastern Asia [2]. Ticks are known for their ability to ingest large volumes of blood from their hosts [3]. Blood contains potentially toxic molecules, such as iron, which can promote the production of hydroxyl radicals and reactive oxygen species (ROS) that can lead to oxidative stress [4]. Therefore, ticks must have protective mechanisms against oxidative stress. Previous studies have shown the role of ferritins, catalases and peroxiredoxins as coping mechanism during periods of oxidative stress [5].

Glutathione S-transferases (GSTs) are enzymes known to conjugate xenobiotic compounds, such as drugs and pesticides, with glutathione (GSH) for their metabolism. Aside from this, they are also involved in the catalysis of fatty acid reduction and the metabolism of phospholipids and DNA hydroperoxidases, which are all products of oxidative stress [6]. Several studies of GSTs either involved measuring their enzymatic activity [7] or analyzing their gene expression profile [8]; however, these methods have limitations. According to Hayes et al. [9], studies of GST activity do not take into consideration GST's ability to bind to molecules other than its substrate that would inhibit its activity. On the other hand, several studies have shown the presence of post transcriptional factors that could present differences between gene and protein expressions of GSTs [10, 11]. Thus, studies involving immunohistochemistry are necessary to establish the relationship between GST localization and its function to fully understand the tick detoxification pathway involving GSTs.

A GST of $H$. longicornis has been previously identified and partially characterized [2]. Additionally, GSTs of other tick species such as Rhipicephalus (Boophilus) microplus, $R$. appendiculatus, Dermacentor variabilis, $R$. (B.) annulatus and $R$. sanguineus, have been identified and characterized $[2,12-16]$. Here we have identified a novel GST from $H$. longicornis and characterized its role through its activity, gene transcription, protein expression, and protein localization during the course of bloodfeeding to be able to evaluate its potential in designing a new method of tick control.

\section{Methods}

\section{Ticks and experimental animals}

The parthenogenetic Okayama strain of $H$. longicornis was used in all experiments throughout this study. Ticks were maintained by feeding on the ears of Japanese white rabbits (KBT Oriental, Saga, Japan) for several generations at the Laboratory of Infectious Diseases, Joint Faculty of Veterinary Medicine, Kagoshima University, Kagoshima, Japan [17]. Rabbits were also used in all tick infestation experiments. Twelve 4-week-old female ddY mice (Kyudo, Kumamoto, Japan) were used for GST antiserum preparation. Experimental animals were kept at $25{ }^{\circ} \mathrm{C}$ and $40 \%$ relative humidity, with a constant supply of water and commercial feeds. The ticks, on the other hand was maintained in glass tubes sealed with cotton plug and maintained at $15{ }^{\circ} \mathrm{C}$ and $80-85 \%$ relative humidity in an incubator until use. The care and use of experimental animals in this study were approved by the Animal Care and Use Committee of Kagoshima University (approval numbers VM15055 and VM15056 for the rabbits and mice, respectively).

\section{Identification and characterization of GST CDNA clones}

The expressed sequence tags (EST) database of $H$. longicornis was analyzed and searched for genes encoding GSTs. Plasmids containing inserts for the two GSTs were extracted using the Qiagen Plasmid Mini Kit (Qiagen, Hilden, Germany) and underwent sequencing using an automated sequencer (ABI PRISM 3100 Genetic Analyzer; Applied Biosystems, Foster City, CA, USA) to determine the full-length sequence. The deduced amino acid translation of GST genes was determined using GENETYX software (Genetyx, Tokyo, Japan). A homologous search of the full-length GST sequences was performed using BLAST programs, through which conserved domains were also identified. The presence of a signal peptide was checked using the SignalP 3.0 prediction server (http://www.cbs.dtu.dk/services/SignalP/), and the predicted molecular weight and isoelectric points (pIs) were determined using the ExPASy server (http:// web.expasy.org/peptide_mass/). Analysis for $\mathrm{N}$-glycosylation was performed using the NetNGLyc 1.0 server (http://www.cbs.dtu.dk/services/NetNGlyc/). A phylogenetic tree was constructed based on the amino acid sequences of GSTs from selected species by the 
neighbor-joining method using the Phylogeny.fr server (http://www.phylogeny.fr/). Multiple sequence alignments between GSTs among tick species were also done using the BOXSHADE software (http://www.ch.embnet.org/ software/BOX_form.html). Molecular models of GSTs were also constructed using PHYRE2 software (http:// www.sbg.bio.ic.ac.uk/phyre2/) and analyzed using PyMOL software (www.pymol.org).

\section{Preparation of recombinant GSTs}

The open reading frames (ORF) of the two GST genes were amplified using gene-specific primers: HIGST BamHI forward, HIGST EcoRI reverse, HIGST2 BamHI forward, and HIGST2 EcoRI reverse (Table 1). PCR was conducted using a KOD-Plus-Neo PCR Kit (Toyobo, Osaka, Japan) following the manufacturer's protocol. The PCR profile was as follows: $94{ }^{\circ} \mathrm{C}$ for $2 \mathrm{~min}, 45$ cycles of the denaturation step at $98{ }^{\circ} \mathrm{C}$ for $10 \mathrm{~s}$, and an annealing/extension step at $68^{\circ} \mathrm{C}$ for $45 \mathrm{~s}$. PCR products were purified using a GENECLEAN II Kit (MP Biomedicals, Solon, OH, USA), and then subcloned into the pRSET A vector (Invitrogen, Carlsbad, CA, USA). The resulting plasmids were checked for accurate insertion through the analysis by restriction enzymes BamHI and EcoRI, and the target sequences were read using the automated sequencer. The plasmids were purified using the Qiagen Plasmid Mini Kit (Qiagen). The purified plasmids were expressed in Escherichia coli BL21 cells, grown in Luria-Bertani (LB) broth medium with ampicillin. The synthesis of recombinant GSTs tagged with histidine was induced with isopropyl $\beta$-D-1-thiogalactiopyranoside (IPTG) at a final concentration of $1 \mathrm{mM}$. Cells were collected by centrifugation, and protein was extracted through ultrasonication. Purification was carried out using a HisTrap column (GE Healthcare, Uppsala, Sweden) and then dialyzed against phosphate buffered saline (PBS). The purity was checked using sodium dodecyl sulphate polyacrylamide gel electrophoresis (SDSPAGE) analysis and Western blotting using the antiHistidine antibody (GE Healthcare). The protein concentration was determined through SDS-PAGE using bovine serum albumin as the standard. Micro BCA Protein Assay Kit (Thermo Scientific, Rockford, IL, USA) was also used to check the protein concentration.

\section{Enzyme activity assay}

The enzymatic activity of recombinant GSTs was measured according to the methods of Habig [18] using 1-chloro-2,4dinitrobenzene (CDNB) (Sigma-Aldrich, St. Louis, MO, USA) as a substrate. Two hundred microliters of the reaction mixture consisting of a final concentration of 1 $\mathrm{mM}$ CDNB dissolved in methanol, $5 \mathrm{mM}$ glutathione, and $120 \mu \mathrm{M}$ recombinant GSTs in $100 \mathrm{mM}$ Tris- $\mathrm{HCl}(\mathrm{pH} 7.5)$ or without recombinant GST for the blank was tested in a 96-well plate. Methanol concentration was maintained at
5\%. Equine liver GST and the $H$. longicornis peroxiredoxin enzyme were used as the positive and negative control, respectively. The absorbance $\left(\mathrm{A}_{340 \mathrm{~nm}}\right)$ was measured each minute in an $\mathrm{SH}-9000$ microplate reader (Corona Electric, Ibaraki, Japan) at $25{ }^{\circ} \mathrm{C}$ for $5 \mathrm{~min}$. The extinction coefficient of $9.6 \mathrm{mM}^{-1} \mathrm{~cm}^{-1}$, corrected for the 96-well microplate light path, was used. Each assay was done in triplicate, and the results were expressed as the mean of three separate experiments. The effect of $\mathrm{pH}$ on the recombinant GSTs was measured, using the previously described procedure and changing the buffer to either $100 \mathrm{mM}$ citrate buffer $(\mathrm{pH}$ 5.0 and 5.5) or Tris- $\mathrm{HCl}$ buffer ( $\mathrm{pH} 6.8,7.5,8.0$ and 9.5).

The same procedure was utilized for enzymatic activity; however, different concentrations of $\operatorname{CDNB}(0.125,0.25,0.5$, 1 and $2 \mathrm{mM}$ ) in methanol and a constant $5 \mathrm{mM} \mathrm{GSH}$ or different concentrations of $\operatorname{GSH}(0.5,1,2$ and $5 \mathrm{mM})$ with a constant $1 \mathrm{mM}$ CDNB in $100 \mathrm{mM}$ Tris- $\mathrm{HCl}$ buffer ( $\mathrm{pH} 7.5)$ were used. Each assay was done in triplicate, and the results are expressed as the mean of three separate experiments. Kinetic constants $K_{m}$ and $V_{\max }$ were calculated from a double-reciprocal plot of $1 / \mathrm{v}$ versus a $1 /[\mathrm{S}]$ or LineweaverBurk plot in which $V_{\max }=1 / \mathrm{y}$-intercept of the regression line and $K_{m}=V_{\max } \times$ slope of the regression line.

\section{Preparation of mouse anti-GST sera}

To prepare mouse anti-GST sera, 6 mice for each GST were used and each mouse was injected intraperitoneally with 0.5 $\mathrm{ml}$ of $200 \mu \mathrm{g} / \mathrm{ml}$ of recombinant GST completely mixed with an equal volume of Freund's Complete Adjuvant (Sigma-Aldrich) to give each mouse $100 \mu \mathrm{g}$ recombinant protein. Immunization was repeated 14 and 28 days after the first immunization; however, recombinant GST was mixed with incomplete adjuvant (Sigma-Aldrich). All sera were collected 14 days after the last immunization. Antisera were tested using Western blotting, using both recombinant GSTs and tick protein.

\section{RNA interference}

RNA interference using double-stranded RNA (dsRNA) was performed to check for cross-reactivity between the GST antisera. The PCR primers used for the synthesis of dsRNA are listed in Table 1. The HlGST and HlGST2 fragments were amplified by PCR from plasmid clones using oligonucleotides, including HIGST T7 forward with HIGST RNAi reverse and HIGST T7 reverse with HIGST RNAi forward primers, as well as HlGST2 T7 forward with HIGST2 RNAi reverse and HIGST2 T7 reverse with HIGST2 RNAi forward primers, to attach the $\mathrm{T} 7$ promoter recognition sites on both forward and reverse ends. Enhanced green fluorescent protein $(E G F P)$ was amplified from $p E G F P$ through PCR using oligonucleotides containing EGFP T7 forward and EGFP T7 reverse primers as well. PCR products were purified using a GENECLEAN II Kit (MP Biomedicals). The T7 
Table 1 Gene-specific primers used in this study. Underlined letters indicate enzyme recognition sites. RNA polymerase promoter sequence is indicated in italic

\begin{tabular}{|c|c|}
\hline Primer & Sequence $\left(5^{\prime} \rightarrow 3^{\prime}\right)$ \\
\hline HIGST real-time forward & CTTCTTGGATCTTGGCGGGT \\
\hline HIGST real-time reverse & CGATGTCCCAGTAGCCGAG \\
\hline HIGST BamHI forward & CGGGATCCATGGCTCCTATTCTCGGCT \\
\hline HIGST EcoRI reverse & CGGAATTCTCAGCAGTCGTCAGCGGGCG \\
\hline HIGST RT forward & ACGTGAAGCTCACCCAGAGCAT \\
\hline HIGST RT reverse & AAGCTAGCCATGTCGCCGTTGA \\
\hline HIGST RNAi forward & GCCTGGCTCAAGGAGAAACACA \\
\hline HIGST RNAi reverse & ACAAAGGCCTTCAGGTTGGGGA \\
\hline HIGST T7 forward & TAATACGACTCACTATAGGGCCTGGCTCAAGGAGAAACACA \\
\hline HIGST T7 reverse & TAATACGACTCACTATAGGACAAAGGCCTTCAGGTTGGGGA \\
\hline HIGST2 real-time forward & CCCTTCCGGGAATGAAGGAG \\
\hline HIGST2 real-time reverse & GATCGCTCAGCAGTCGTCAG \\
\hline HIGST2 BamHI forward & CGGGATCCATGGCCCCTGTGCTGGGATA \\
\hline HIGST2 EcoRI reverse & CGGAATTCTCAGCAGTCGTCAGCGGGCG \\
\hline HIGST2 RT forward & ACGTCAAGCTGACGCAGAGCAT \\
\hline HIGST2 RT reverse & ATGGGCCAAGCCTTGAAGCGAT \\
\hline HIGST2 RNAi forward & AGGATAAAAGGTACGGCTTCGGCA \\
\hline HIGST2 RNAi reverse & TITCACGATCTGGAGAGCCTCGTA \\
\hline HIGST2 T7 forward & TAATACGACTCACTATAGGAGGATAAAAGGTACGGCTTCGGCA \\
\hline HIGST2 T7 reverse & TAATACGACTCACTATAGGTITCACGATCTGGAGAGCCTCGTA \\
\hline PO real-time forward & CTCCATTGTCAACGGTCTCA \\
\hline PO real-time reverse & TCAGCCTCCTTGAAGGTGAT \\
\hline L23 real-time forward & CACACTCGTGTTCATCGTCC \\
\hline L23 real-time reverse & ATGAGTGTGTTCACGTTGGC \\
\hline Actin real-time forward & ATCCTGCGTCTCGACTTGG \\
\hline Actin real-time reverse & GCCGTGGTGGTGAAAGAGTAG \\
\hline Actin RT forward & CCAACAGGGAGAAGATGACG \\
\hline Actin $\mathrm{RT}$ reverse & ACAGGTCCTTACGGATGTCC \\
\hline Tubulin real-time forward & TTCAGGGGCCGTATGAGTAT \\
\hline Tubulin real-time reverse & TGTTGCAGACATCTTGAGGC \\
\hline EGFP T7 forward & TAATACGACTCACTATAGGGACGTAAACGGCCACAAGTT \\
\hline EGFP T7 reverse & TAATACGACTCACTATAGGTGCTCAGGTAGTGGTTGTCG \\
\hline
\end{tabular}

RiboMAX Express RNAi System (Promega, Madison, WI, USA) was used to synthesize dsRNA by in vitro transcription. The successful construction of dsRNA was confirmed by running $1 \mu \mathrm{l}$ of the dsRNA products in $1.5 \%$ agarose gel in a TAE buffer. $0.5 \mu \mathrm{l}$ of $2 \mu \mathrm{g} / \mu \mathrm{l}$ of HlGST, HlGST2, and HlGST1/2 (HlGST and HlGST2 mixed at $2 \mu \mathrm{g} / \mu \mathrm{l}$ concentration each) dsRNA dissolved in high-purity water were injected to the hemocoel of unfed adult female ticks through the fourth coxae to give each tick $1 \mu \mathrm{g}$ of dsRNA. A total of 10 ticks per group were injected with dsRNA. The control group was injected with EGFP dsRNA. After injection, the ticks were held for $24 \mathrm{~h}$ in a $25{ }^{\circ} \mathrm{C}$ incubator to check for mortality resulting from injury during injection. The ticks were then to feed on rabbits for four days, and then the partially fed ticks were collected. Total RNA was extracted from five whole 4-day-fed ticks, and their cDNA was synthesized. cDNA was subjected to RT-PCR with a Hot Start Pol system (Jena Bioscience, Jena, Germany) using GST-specific primers, HIGST RT forward and HIGST RT reverse primers, and HIGST2 RT forward and HIGST2 RT reverse primers, following the manufacturer's instructions. The PCR cycle profile was as follows: $94{ }^{\circ} \mathrm{C}$ for $8 \mathrm{~min}, 30$ cycles of a denaturation 
step at $94{ }^{\circ} \mathrm{C}$ for $30 \mathrm{~s}$, an annealing step at $68{ }^{\circ} \mathrm{C}$ for 60 $\mathrm{s}$, and an extension step at $72{ }^{\circ} \mathrm{C}$ for $60 \mathrm{~s}$. The PCR products were run in $1.5 \% \mathrm{TAE}$ agarose gels and stained with ethidium bromide. Actin was used as a loading control. The absence of bands corresponding to HlGST and HlGST2 in their corresponding GST knockdown group demonstrates that silencing was successful (Additional file 1: Figure S1). Proteins were extracted and prepared from the remaining ticks of different knockdown groups for Western blotting using the prepared anti-GST sera. Mouse tubulin antiserum was used as a control for Western blotting. The absence of signals corresponding to HIGST in the HlGST knockdown group and HIGST2 in the HlGST2 knockdown group demonstrates that the antibodies produced are specific and do not cross react; therefore, they could be used in succeeding experiments (Additional file 1: Figure S1).

\section{Total RNA extraction and real-time PCR analysis}

Total RNA was extracted from different developmental stages (egg, larva, nymph and adult) and organs of adult female ticks, including the midgut, salivary glands, ovaries, fat body, and hemocytes during blood-feeding. Whole tick samples were homogenized using an automill (Tokken, Chiba, Japan) and were added to TRI Reagent ${ }^{\oplus}$ (Sigma-Aldrich). On the other hand, organs such as salivary glands, midguts, fat bodies, and ovaries were dissected and washed in PBS, placed directly in tubes with the TRI Reagent, and homogenized. Hemocytes were collected through the legs of ticks as previously described [19]. RNA extraction was performed following the manufacturer's protocol. Subsequently, single-strand cDNA was prepared by reverse transcription using the ReverTra Ace $^{\curvearrowleft}$ cDNA Synthesis Kit (Toyobo), following the manufacturer's protocol. Transcription analysis of HlGST and HlGST2 genes was performed through real-time PCR using THUNDERBIRD ${ }^{\mathrm{Tm}}$ SYBR $^{\odot}$ qPCR Mix (Toyobo) with an Applied Biosystems 7300 RealTime PCR System using gene-specific primers, HIGST real-time forward and HIGST real-time reverse, and HIGST2 real-time forward and HIGST2 real-time reverse primers (Table 1). Standard curves were made from fourfold serial dilutions of the cDNA of adult ticks fed for 3 days. The PCR cycle profile was as follows: $95{ }^{\circ} \mathrm{C}$ for $10 \mathrm{~min}, 40$ cycles of a denaturation step at $95{ }^{\circ} \mathrm{C}$ for $15 \mathrm{~s}$, and an annealing/extension step at $60{ }^{\circ} \mathrm{C}$ for $60 \mathrm{~s}$. The data was analyzed with Applied Biosystems 7300 system SDS software. In the first step of real-time PCR, actin, tubulin, PO, and L23 genes were evaluated for standardization. PO genes were selected as an internal control for the whole ticks, while L23 genes were chosen for the tick organs.

\section{Protein extraction and Western blotting analysis}

Protein was extracted at different developmental stages and from different organs of adult female ticks during bloodfeeding. For different developmental stages, whole tick samples were homogenized using an automill (Tokken), and then suspended in PBS treated with Complete Mini Proteinase Inhibitor Cocktail Tablets (Roche, Mannheim, Germany). Eggs and organs were homogenized using a mortar, and they were also suspended in PBS treated with a proteinase inhibitor. After sonication and recovery of the supernatant, tick proteins were separated with a $12 \%$ SDSpolyacrylamide gel electrophoresis (SDS-PAGE) and transferred to a polyvinylidene difluoride (PVDF) membrane (Millipore, Billerica, MA, USA). The membrane was blocked overnight with 3\% skim milk in PBS with $0.05 \%$ Tween 20, and then incubated with a primary antibody using mouse anti-GST sera (1:1000 dilution) for $1 \mathrm{~h}$. $\beta$ tubulin was used as a control [20]. After incubation with horseradish peroxidase-conjugated goat anti-mouse IgG (1:50,000 dilution; DakoCytomation, Glostrup, Denmark) for $1 \mathrm{~h}$, the signal was detected using Clarity ${ }^{\text {TM }}$ Western ECL Substrate (Bio-Rad Laboratories, Hercules, CA, USA) or Amersham $^{\text {тм }}$ ECL $^{\text {тм }}$ Prime Western Blotting Detection Reagent (GE Healthcare, Buckinghamshire, UK). It was analyzed using FluorChem FC2 software (Alpha Innotech, San Leandro, CA, USA).

\section{Indirect immunofluorescent antibody test}

An indirect immunofluorescent antibody test (IFAT) was performed to demonstrate the endogenous localization of GSTs, as described previously [21]. The salivary glands, midguts, ovaries, and fat bodies of ticks at different stages of blood-feeding were immediately dissected under a stereo microscope. Dissected organs were fixed overnight in $4 \%$ paraformaldehyde in PBS with $0.1 \%$ glutaraldehyde and then washed with different concentrations of sucrose in PBS. The organs were embedded in Tissue-Tek OCT Compound (Sakura Finetek Japan, Tokyo, Japan) and then frozen using liquid nitrogen. Sections $10 \mu \mathrm{m}$ thick were cut using a cryostat (Leica CM3050; Leica Microsystems, Wetzlar, Germany) and placed on MAS-coated glass slides (Matsunami Glass, Osaka, Japan). After blocking for $1 \mathrm{~h}$ with $5 \%$ skim milk in PBS at room temperature, sections were incubated with a 1:100 dilution of anti-GST sera overnight at $4{ }^{\circ} \mathrm{C}$. Normal mouse serum at the same dilution was used as a negative control. Sections were washed with PBS and then incubated with Alexa Fluor 488-conjugated goat anti-mouse IgG (1: 1000; Invitrogen) for $1 \mathrm{~h}$ at room temperature. After washing with PBS, sections were mounted in Vectashield with DAPI (Vector Laboratories, Burlingame, CA, USA). Images were taken using a confocal fluorescence microscope mounted with an LSM 700 (Carl Zeiss, Jena, Germany). 


\section{Statistical analysis}

Student's t-test was used to analyze data from the realtime PCR of ticks and organs. A significant difference is defined as $P<0.05$. All experiments were done at least twice for validation.

\section{Results}

\section{Identification and characterization of GST CDNAs}

Two cDNAs encoding glutathione S-transferase were identified and cloned. The open reading frame of the first GST gene contains 672 base pairs (bp) from the predicted start codon to the predicted end codon, encodes 223 amino acid polypeptides, and has a calculated molecular weight of $\sim 25.7 \mathrm{kDa}$ and a pI of 7.67 . No glycosylation site or signal peptide was predicted. An Nterminal domain containing the glutathione binding site and a C-terminal domain containing the 105 amino acids substrate binding site were present. Since BLAST and multiple sequence alignment analysis showed that it has $99 \%$ homology with the previously identified $H$. longicornis GST (HlGST) (GenBank: AAQ74441), it is considered the same as HIGST (Additional files 2 and 3: Figures S2 and S3). It also showed high homology to the GSTs of D. variabilis (91\%), R. sanguineus (87\%), and $I$. scapularis (GenBank: XP_002401749.1) (85\%) (Fig. 1).
On the other hand, the open reading frame of the second GST has 693 bp from the predicted start codon to the predicted end codon, encodes 230 amino acid polypeptides, and has a calculated molecular weight of $\sim 26.3$ $\mathrm{kDa}$ and a pI of 6.83. No glycosylation site or signal peptide was predicted. It also has an N-terminal domain containing the glutathione binding site and a C-terminal domain containing the 65 amino acids substrate binding site. (Additional files 2 and 3: Figures S2 and S3). We found the second GST novel and submitted to GenBank where it was assigned the accession number LC169599. We refer to the novel GST as HIGST2. HIGST2 has 64\% homology with the putative GST of I. scapularis (GenBank: XP_002434207.1) (Fig. 1).

A phylogenetic tree was also constructed using amino acid sequences of GSTs from different species to further analyze the identity of the GSTs (Fig. 2). HIGST was found to be closely related to the mu-class GSTs of $D$. variabilis and I. scapularis (GenBank: XP_002401749.1), while HIGST2 is closely related to I. scapularis GST (GenBank: XP_002434207.1). These results demonstrate that the newly identified HIGST2 also belongs to the mu-class of GST, due to its more than $40 \%$ similarity to the mammalian mu-class of GST [6] and the presence of the mu-loop (Additional file 3: Figure S3) [22].

HlGST
HlGST2
H. longicornis
D. variabilis
R. sanguineus
I. scapularis A
I. scapularis B

HlGST
HIGST2
$H$. longicornis
D. variabilis
R. sanguineus
I. scapularis A
I. scapularis B

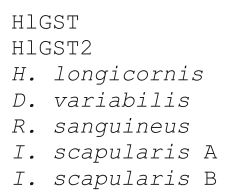

I. scapularis $\mathrm{B}$

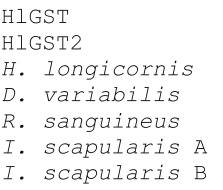

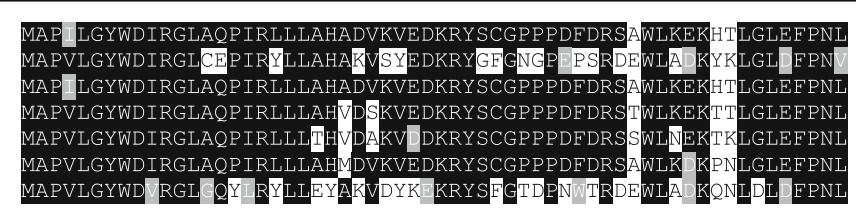
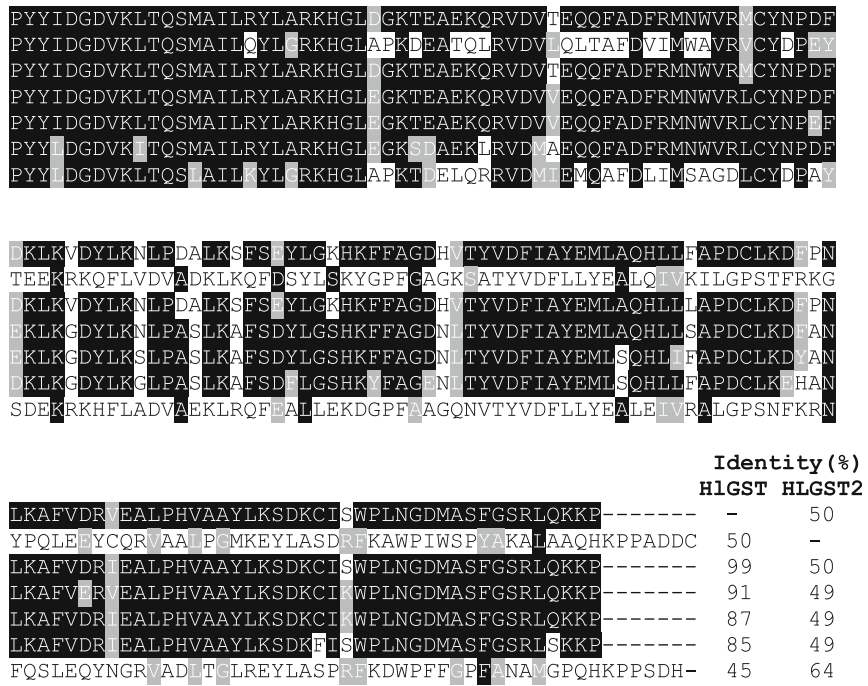

Fig. 1 Multiple sequence alignment of the deduced amino acid sequences of HIGST and HIGST2 with other tick GSTs. Identical residues are shaded black, while similar residues are shaded gray. The percent identities with HIGST and HIGST2 are placed at the end of the sequences. The GenBank accession numbers for GST sequences are as follows: Haemaphysalis longicornis (AAQ74441.1), Dermacentor variabilis (ACF35504.1), Rhipicephalus sanguineus (AGK29895.1), Ixodes scapularis A (XP_002401749.1) and Ixodes scapularis B (XP_002434207.1) 


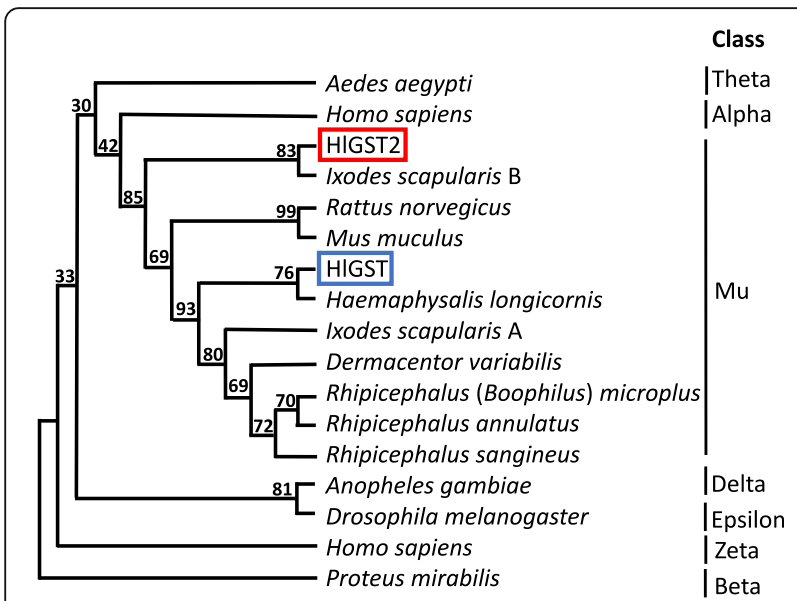

Fig. 2 Phylogenetic tree of GSTs from different species of ticks, selected vertebrates, and invertebrates. A dendogram was created by the neighbor-joining method based on the deduced amino acid sequence of GSTs. Bootstrap values are placed at the nodes. GenBank accession numbers are as follows: Aedes aegypti (Theta), Q16X19; Homo sapiens (Alpha), P08263; Ixodes scapularis A, XP 002401749.1; Ixodes scapularis B, XP_002434207.1; Rattus norvegicus, NP_803175.1; Mus muculus, NP_032209.1; Haemaphysalis longicornis, AAQ7444.1; Dermacentor variabilis, ACF35504.1; Rhipicephalus (Boophilus) annulatus, ABR24785.1; Rhipicephalus sanguineus, AGK29895.1; Anopheles gambiae (Delta), Q8MUS1; Drosophila melanogaster, (Epsilon) Q7KK90; Homo sapiens, (Zeta) O43708; and Proteus mirabilis, (Beta) P15214

\section{Expression of recombinant GSTs}

The expression of recombinant GSTs was performed using E. coli BL21 cells with pRSET A as the vector. The expression was induced by IPTG at a final concentration of $1 \mathrm{mM}$ at $37^{\circ} \mathrm{C}$. After expression, purification by affinity chromatography was carried out. The eluted protein was checked by $12 \%$ SDS-PAGE and seen as single bands, which indicated purity. The purified recombinant HIGST molecular weight was approximately $28 \mathrm{kDa}$, while recombinant HIGST2 has an approximate molecular weight of $29 \mathrm{kDa}$. Recombinant GSTs contain fragments of the his-tag protein, which could account for the difference in the calculated molecular weights of $25.7 \mathrm{kDa}$ and $26.3 \mathrm{kDa}$ for HIGST and HIGST2, respectively (Fig. 3). Western blotting using an anti-histidine antibody showed positive signals, indicating the presence of histidinetagged GSTs (Fig. 3). These results demonstrate the successful expression of histidine-tagged recombinant GST using the E. coli expression system.

\section{GST specific enzymatic activity}

The specific activity of recombinant HIGST and HIGST2 was determined through its ability to conjugate CDNB. CDNB has been used as a substrate in previous studies, and it has shown that mu-class GSTs react better with CDNB as compared with other substrates, such as 1,2dichloro-4-nitrobenzene (DCNB) [15]. The enzymatic activity of recombinant GSTs toward CDNB is $9.75 \pm 3.04$ units/mg protein for recombinant HIGST and $11.63 \pm 4.08$ units/mg protein for recombinant HlGST2 (Table 2). Recombinant HIGST2 appears to have higher enzymatic activity than HlGST. To further characterize the GSTs, the optimum $\mathrm{pH}$ of the activity of recombinant GSTs was determined by checking its activity in buffer with different $\mathrm{pHs}$. The $\mathrm{pH}$ at which the activity of both GSTs is the highest, or the optimum $\mathrm{pH}$, is 7.5-8.0 (Fig. 4). These results demonstrate that the expressed recombinant GSTs could conjugate GSH with the substrate CDNB and possess almost the same rate of conjugation activity in a similar range of $\mathrm{pH}$.

\section{Enzyme kinetics of GSTs}

To further establish the characteristics of these GSTs, we determined the enzyme kinetics constants of these GSTs, using the Michaelis-Menten equation and the Lineweaver-Burk plot. When the concentration of GSH is kept constant, HlGST has a $V_{\max }$ of $11.70 \pm 1.92$ units/mg protein and a $K_{m}$ of $0.82 \pm 0.14 \mathrm{mM}$, whereas HIGST2 has a $V_{\text {max }}$ of $14.72 \pm 0.56$ units $/ \mathrm{mg}$ protein and a $K_{m}$ of $0.61 \pm 0.20 \mathrm{mM}$. Meanwhile, when the concentration of CDNB is kept constant, HIGST has a $V_{\max }$ of $10.40 \pm 1.77$ units/mg protein and a $K_{m}$ of $0.64 \pm 0.32$ $\mathrm{mM}$, whereas HlGST2 has a $V_{\max }$ of $11.01 \pm 0.21$ units $/ \mathrm{mg}$ protein and a $K_{m}$ of $0.53 \pm 0.19 \mathrm{mM}$ (Table 3). These results demonstrate that recombinant GSTs have a high affinity toward GSH and the known GST substrate, CDNB. They also indicate a high ability of the recombinant GSTs to conjugate with CDNB and GSH.

\section{Transcription profiles of GSTs}

The transcription profiles of HlGST and HlGST2 genes from different developmental stages and organs of ticks during blood-feeding were checked using real-time PCR (Fig. 5). It was observed that both HlGST and HlGST2 genes were constitutively expressed at all developmental stages, with increasing expression observed toward engorgement in the nymph and adult stages for HlGST and in all stages for HlGST2 genes. Relatively strong expressions of both HIGST and HIGST2 genes were observed in the eggs. The gene transcription during the larval stages shows that HlGST appears to be maintained at a high transcription level. Both HlGST and HlGST2 genes were also expressed in all organs. In different organs of female ticks, such as the salivary glands, ovaries, fat bodies, and hemocytes, gene expression increases as blood-feeding progresses, continuously increasing until engorgement. In the midgut, increasing transcription during the course of blood-feeding was also observed, except in the engorged stage, wherein there is a decreased expression of both HlGST and HlGST2 genes. These results demonstrate that blood-feeding can trigger an upregulation of the transcription of GST genes. This fact 
a

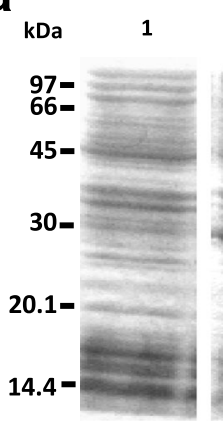

b

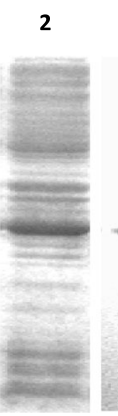

3

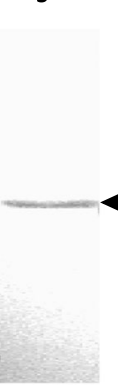

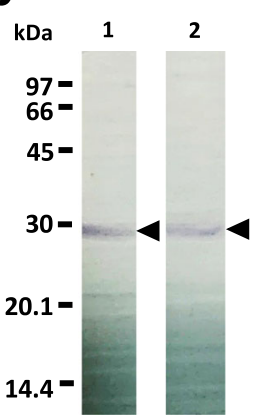

Fig. 3 SDS-PAGE (a) and Western blotting (b) of recombinant GSTs. a The column farthest left includes markers of molecular weights. Lane 1: bacterial lysate of empty vector; Lane 2: bacterial lysate of HIGST after induction by 1 mM IPTG; Lane 3: bacterial lysate of HIGST after purification by HisTrap affinity chromatography; Lane 4: bacterial lysate of HIGST2 after induction by 1 mM IPTG; Lane 5: bacterial lysate of HIGST2 after purification by HisTrap affinity chromatography. The lysates were run on a 12\% SDS-PAGE gel. Gels were stained using Coomassie Blue staining solution. b The column farthest left indicates molecular weight markers. Lane 1: recombinant HIGST; Lane 2: recombinant HIGST2. Bands were visualized using 5-Bromo-4-chloro-3-indolylphosphate/Nitroblue Tetrazolium (BCIP/NBT) Calbiochem ${ }^{\circledast}$ (Merck KGaA, Darmstadt, Germany). Arrowheads indicate the bands for recombinant HIGST and HIGST2 proteins

could indicate the genes' possible role in coping with oxidative stress caused by blood-feeding.

\section{Protein expression profiles of GSTs}

The protein expression of endogenous GSTs in different developmental stages and organs was determined through Western blotting analysis using specific anti-GST sera (Fig. 6 and Additional file 4: Figure S4). The GST protein expression during the larval stage has a tendency to decrease during the course of blood-feeding to engorgement, while in the nymph and adult stages, protein expression tends to increase during feeding and then decrease at the end of blood-feeding. In the midgut and hemocytes, GST expression increased during the partially fed state of blood-feeding; however, in other organs examined, such as the salivary glands, fat body, and ovaries, the expression of both HIGST and HlGST2 proteins decreased as bloodfeeding progressed to engorgement. These results demonstrate that GST protein expression in ticks is upregulated during periods of increased oxidative stress, specifically on

Table 2 Specific activity of each recombinant GST with the substrate CDNB. Values are presented as mean \pm SD. The concentration of CDNB and GSH used are $1 \mathrm{mM}$ and $5 \mathrm{mM}$, respectively. Each experiment was performed at least three times and each assay was run in triplicate

\begin{tabular}{ll}
\hline Enzyme & Enzyme activity (units/mg protein) \\
\hline Equine liver GST & a \\
rHIPRX2 $^{b}$ & $11.01 \pm 2.60$ \\
rHIGST $^{c}$ & nd \\
rHIGST2 $^{d}$ & $9.24 \pm 3.05$ \\
\hline
\end{tabular}

Abbreviation: $n d$ none detected

${ }^{a}$ Equine liver GST was used as a positive control

${ }^{\mathrm{b}}$ Recombinant $H$. longicornis peroxiredoxin2 was used as the negative control

'Recombinant HIGST

${ }^{\mathrm{d}}$ Recombinant HIGST2 organs exposed to such oxidative stress, such as the midgut. This further confirms the anti-oxidant function of GSTs during blood-feeding.

\section{Localization of HIGST and HIGST2 in different organs using IFAT}

The localizations of endogenous HIGST and HlGST2 in partially fed adult salivary glands, midguts, fat bodies, ovaries, and hemocytes were demonstrated using IFAT (Fig. 7). Both HIGST and HIGST2 are found in the cytoplasm of cells. GSTs in the salivary glands are observed in the ducts and its epithelial cells of the nondegenerated acinus. A positive reaction was observed in the apical part of the epithelium of the midgut cells. In the fat body, a positive reaction was observed in the tracheal complex. In the ovaries, a positive reaction for GST was observed mainly in the pedicels and ovarian wall. Positive fluorescence in the cytoplasm of hemocytes was also observed. However, strong HlGST2 fluorescence was observed on the periphery of the hemocytes, while for HIGST, it was observed at scattered locations throughout.

IFAT was used to further characterize the role of GSTs in major organs such as salivary glands, midguts, and ovaries from female ticks at different blood-feeding stages (Fig. 8). In the salivary glands, GSTs are spread throughout the acinus; however, during blood-feeding, GSTs shift to being more expressed in the ducts during the partially fed and engorged stages. In the unfed midgut, fluorescence is also scattered throughout the digestive cells, then shifts toward the apical part of the epithelium in partially fed ticks and toward the basal membrane in the engorged stage. Fluorescence is limited in the ovarian wall and the pedicels of the ovary, but not in the oocytes, throughout the duration of blood-feeding. These results demonstrate 

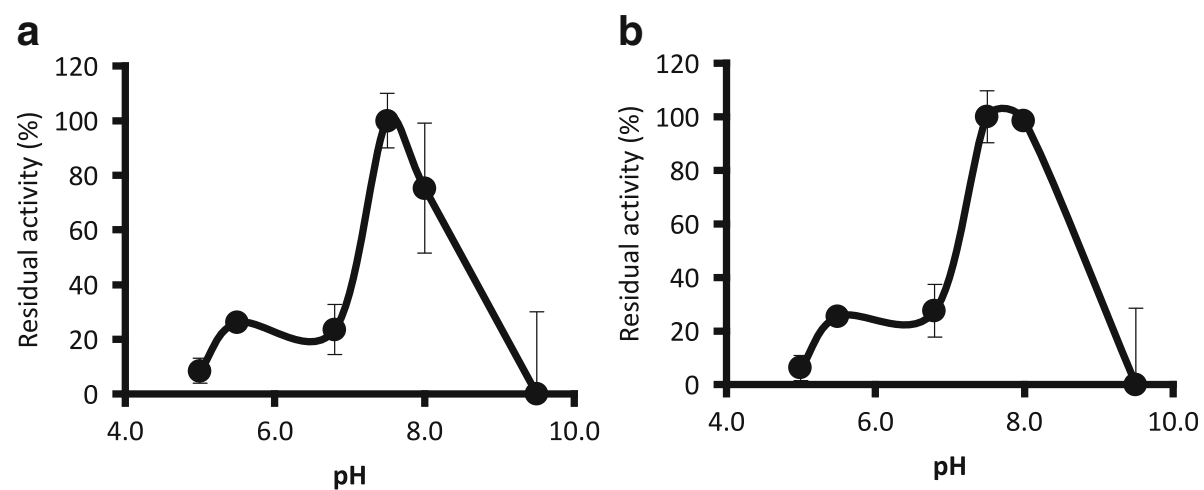

Fig. 4 Effect of pH on the enzymatic activity of recombinant HIGST (a) and HIGST2 (b). Buffers were $0.1 \mathrm{M}$ citrate for pH 5.0-5.5 and Tris-HCl for $\mathrm{pH}$ 6.5-8.5. Error bars represent the standard deviation of three replicates, and the remaining activities were recorded as percentages relative to the highest activity

that GST proteins tend to vary depending on the blood-feeding stage and eventually the levels of oxidative stress.

\section{Discussion}

Multiple isoenzymes of GSTs have been observed in all eukaryotes [6]. In silico analysis of the Ixodes scapularis gene database showed 35 genes of GSTs, of which 14 belong to the mu-class GST [23]. In Dermacentor variabilis and Rhipicephalus (Boophilus) annulatus, multiple GSTs have also been found $[14,24]$. The presence of multiple forms of GSTs could prove to be important for species to counter most, if not all, foreign or endogenous compounds that could affect them [15]. One GST has already been identified and partially characterized in $H$. longicornis [2]. Here, a novel GST from $H$. longicornis, HIGST2, was identified and characterized with the previously identified GST, HIGST.

The smaller predicted substrate binding site of HIGST2 located at the $\mathrm{C}$-terminal domain could account for the faster activity rate of HIGST2 because of the possibly fewer enzyme-substrate interactions that could slow the rate of product release from the enzymes [25].
The effect of $\mathrm{pH}$ on enzymatic activity has been an important factor in determining the protein structure and function [15]. The optimal $\mathrm{pH}$ for activity toward CDNB of 7.5-8.0 is in the same range as that of $R$. (B.) annulatus GST. The optimum pH could vary depending on the compound used to test the GST activity, which could range from 6.5-9.5. If we consider only $\mathrm{CDNB}$, the values also represent the modal tendency of several species at $\mathrm{pH}$ 7.5-8.0. Loss or decrease of enzymatic activity at lower or higher $\mathrm{pH}$ could be the result of the ionizing activity of both CDNB and GSH that occurs at $\mathrm{pH} 6-7[15,26]$. This result could indicate stability and the capability of GSTs to function in conditions closer to intracellular conditions.

The $V_{\max }$ values for both recombinant GSTs are below those of the recombinant GST of $R$. (B.) annulatus (rBaGST), which are 75.2 units/mg protein for CDNB and 48.8 units/mg protein for $\mathrm{GSH}$, it is important to consider that the presence of galactosidase in $\mathrm{rBaGST}$ or the histidine tag in $H$. longicornis recombinant GSTs could result in an altered level of activity of recombinant GSTs. The relatively low $K_{m}$ values $(<1)$ of both GSTs for both GSH and CDNB may indicate a high rate of conjugation that could be attributed to the enzymes [22].

Table 3 Recombinant GST kinetic constants. Values are presented as mean \pm SD. Each experiment was performed at least three times and each assay was run in triplicate

\begin{tabular}{|c|c|c|}
\hline Enzyme & CDNB kinetic constant ${ }^{a}$ & GSH kinetic constant $^{\mathrm{b}}$ \\
\hline \multicolumn{3}{|l|}{$\mathrm{rHIGST}$} \\
\hline$V_{\max }$ (units/mg protein) & $11.70 \pm 1.92$ & $10.40 \pm 1.77$ \\
\hline$K_{m}(\mathrm{mM})$ & $0.82 \pm 0.14$ & $0.64 \pm 0.32$ \\
\hline \multicolumn{3}{|l|}{$\mathrm{rHIGST} 2^{\mathrm{d}}$} \\
\hline$V_{\text {max }}$ (units/mg protein) & $14.72 \pm 0.56$ & $11.01 \pm 0.21$ \\
\hline$K_{m}(\mathrm{mM})$ & $0.61 \pm 0.20$ & $0.53 \pm 0.19$ \\
\hline
\end{tabular}

${ }^{a} \mathrm{CDNB}$, the common substrate, is used in increasing concentration from $0.125-2 \mathrm{mM}$ to determine the kinetic constants

${ }^{\mathrm{b}} \mathrm{GSH}$ is used in increasing concentration for $0.5-5 \mathrm{mM}$ to determine the kinetic constants

'Recombinant HIGST

${ }^{d}$ Recombinant HIGST2 


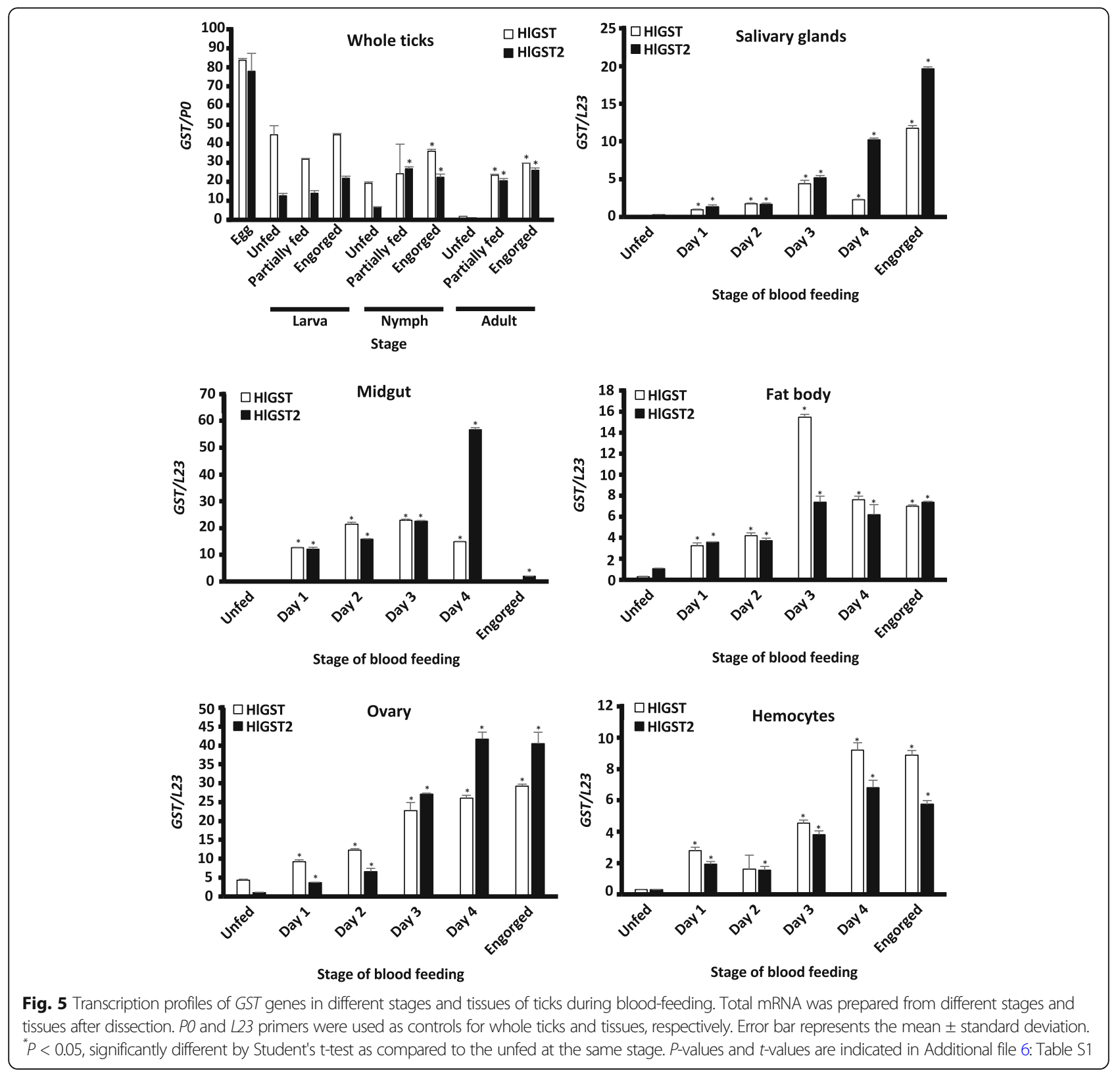

These $K_{m}$ values are close to the $K_{m}$ values for rBaGST, which are $0.57 \mathrm{mM}$ and $0.79 \mathrm{mM}$ for functions of CDNB and GSH, respectively [15]. The $K_{m}$ values of GSH are also close to the values frequently cited in various literature (61\%), which fall in a range of $0.19-0.79 \mathrm{mM}$ [26]. Thus, it is reasonable to think that this newly identified HIGST2 of the hard tick, $H$. longicornis, could provide the tick with a coping mechanism for metabolizing xenobiotic and endogenous products. In addition, these enzyme kinetic parameters could be a basis for comparison for future inhibition studies, in which changes in these values could determine the type of inhibition if an inhibitor is added.

Upregulation of GST genes during blood-feeding suggest the importance of GSTs to oxidative stress management.
It has also been assumed that reactive oxygen is a transduction signal that mediates the gene transcription of GSTs [27]. Thus, during blood-feeding, when the intracellular digestion of blood is high, high levels of reactive oxygen species are produced, which could induce the transcription of GST genes [14]. Upregulation brought about by blood-feeding was also observed in other bloodfeeding arthropods, such as the Aedes aegypti [7], and in other ticks, such as I. ricinus and $R$. (B.) microplus [13, 28]. A high gene transcription profile is observed in eggs since they undergo rapid metabolism due to embryonic development, which could result in the production of an endogenous toxic substance in the eggs; thus, detoxification enzymes are important [5]. Interestingly, the downregulation of GST 


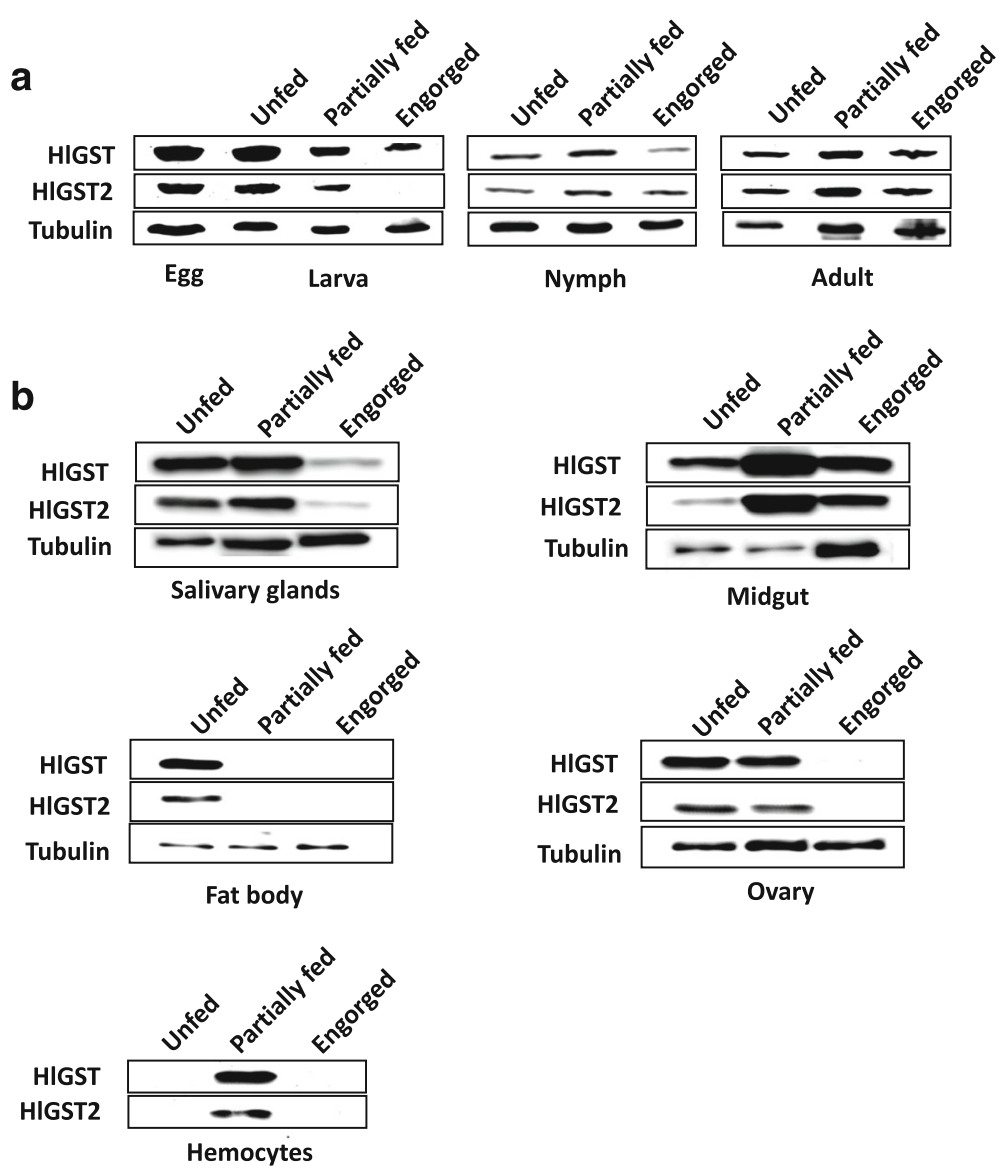

Fig. 6 Expression profiles of GSTs in different tick stages (a) and organs (b) during blood-feeding. Proteins were prepared from different stages and tissues after dissection. Antiserum against tubulin was used as a control for Western blotting. Western blotting results are shown as representative data of three separate experiments showing the same trend. Since no band can be seen using the tubulin antisera on hemocytes, the protein concentration was determined using Micro BCA and maintained at $390 \mathrm{ng}$ before loading for Western blotting

genes during blood-feeding was only observed in the engorged midgut. This could indicate that during this state, the amount of oxidative stress in midgut cells is reduced. The decreased expression could be a result of the nature of blood-feeding in ticks. At the start of blood-feeding, gut epithelia undergo a slow feeding phase, in which the tick prepares its midgut cells for blood intake. Here, some undifferentiated cells begin to differentiate and proliferate. This is also the period in which there is a rapid digestion of ingested cells. In effect, during this stage, ticks are more prone to oxidative stress brought about by rapid metabolism due to cell differentiation and proliferation, and the lysis of ingested cells that leads to the liberation of compounds may also trigger oxidative stress, such as heme aggregates. Afterward, ticks undergo a fast feeding period and eventually drop off the host. During this stage, the midgut would then act as a blood reservoir and the rate of intracellular digestion also becomes low [29]. Low intracellular digestion also results in low ROS emergence and low iron metabolism. The downregulation of mu-class GSTs was also observed in engorged midgut cells of I. ricinus. [14]. Since GST proteins are said to be transcriptionally regulated [27], protein expression in the midgut also appeared to decrease during the engorged stage.

Western blotting analysis revealed decreasing expression in several organs, such as salivary glands, fat bodies, and ovaries, as compared with their increasing gene transcription profile. The decreased oxidative stress during the engorged stage, even with increased transcription in these organs, resulted in an expression level of GST proteins below the Western blotting's capability to detect. The movement of heme, a potentially oxidant molecule, through its carrier protein throughout blood-feeding and, most especially, during the post attachment stage [30, 31], could trigger the upregulation of gene transcription in these organs.

In the salivary glands, the decrease in GST protein expression could also be due to GSTs being secreted through the saliva during the fully engorged stage, as previously observed in other tick species, such as $H$. 

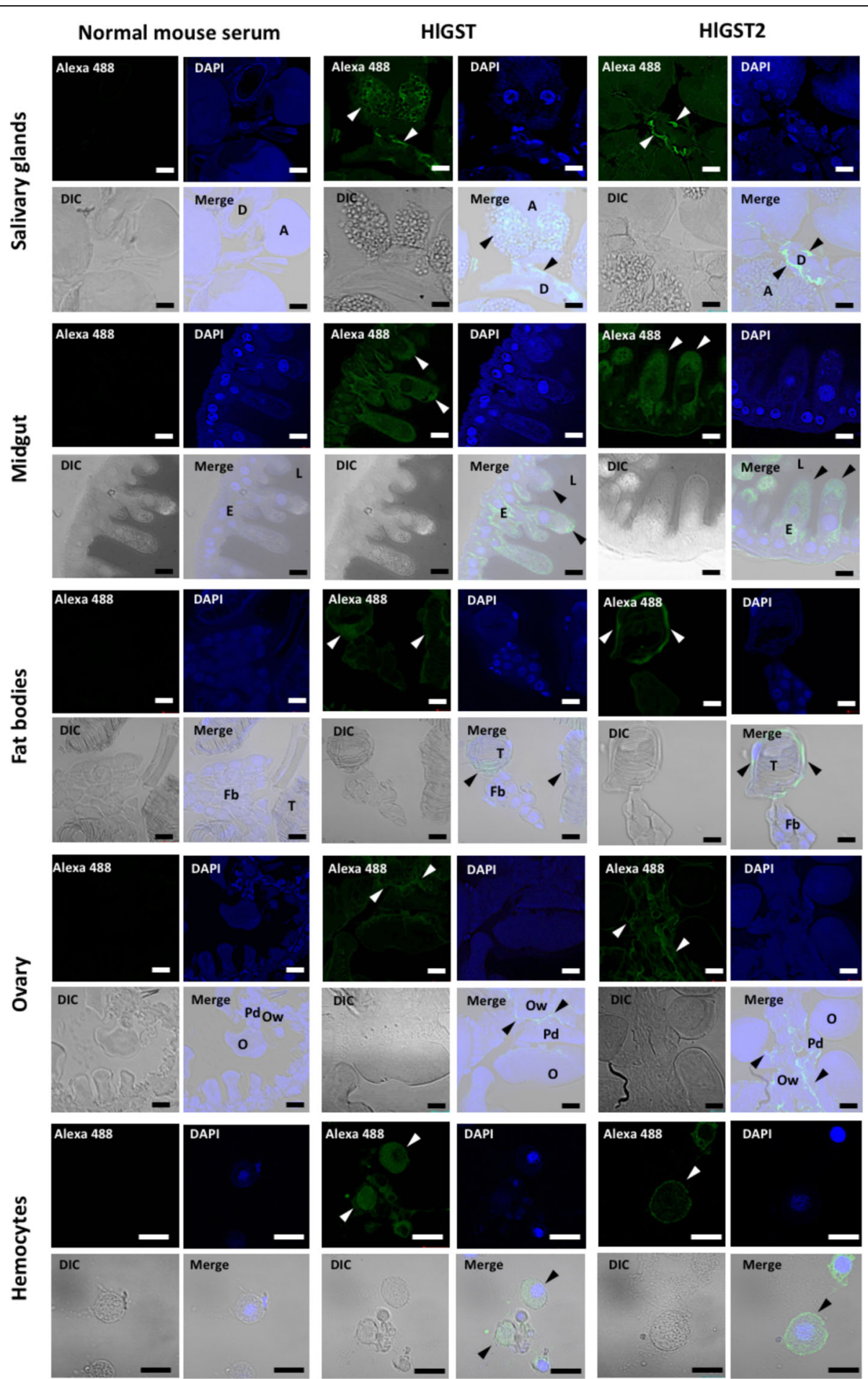

Fig. 7 Localization of GSTs in tissues of partially fed adult ticks. Immunofluorescent antibody test (IFAT) was used to determine the localization of the GSTs in the different tissues of ticks. Antiserum against HIGST or HIGST2 was used for the primary antibody, anti-mouse lgG conjugated with Alexa 488 was used for the secondary antibody, and nuclei were visualized using DAPI. Normal mouse serum was used for a control. The tissues were visualized using confocal microscope. Abbreviations: Salivary glands ( $A$, acinus; D, salivary ducts); Midgut ( $E$, enterocytes; L, lumen; Fat bodies ( $\mathrm{T}$, tracheal complex; Fb, fat body cells); Ovary (O, oocyte; Pd, pedicel; OW, ovarian wall). Arrows show positive GST fluorescence. Scale-bars: 20 Hm 

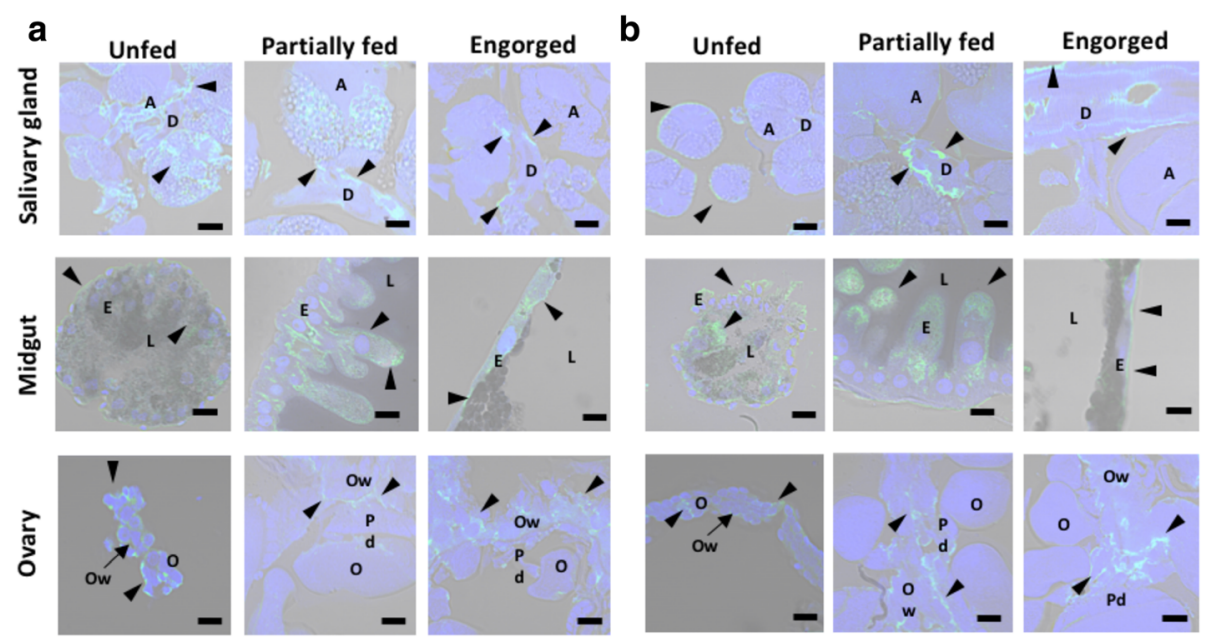

Fig. 8 Examination of HIGST (a) and HIGST2 (b) in selected tissues during blood-feeding. The salivary glands, midgut, and ovary were observed during blood-feeding of adult ticks by indirect immunofluorescent antibody test (IFAT) using a confocal laser scanning microscope. Antiserum against HIGST or HIGST2 was used for the primary antibody, anti-mouse lgG conjugated with Alexa 488 was used for the secondary antibody, and nuclei were visualized using DAPI. Normal mouse serum was used for a control. Abbreviations: Salivary glands (A, acinus; D, salivary ducts); Midgut (E, enterocytes; L, lumen); Ovary (O, oocyte; Pd, pedicel; Ow, ovarian wall). Arrows show the positive fluorescence of GST. Scale-bars: $20 \mu \mathrm{m}$

longicornis, I. scapularis, and Amblyomma americanum [32-34]. IFAT results also demonstrated this possible release, as manifested by the apparent shift of GSTs from the acinus toward the salivary ducts during bloodfeeding. The release of GST from its cytosolic localization has also been reported in mammalian organs such as plasma from the platelets, bile from the liver, and seminiferous tubule fluid from the testes. The release is said to be an energy-requiring active process rather than a secretory process [35-37]. The release could be a possible extracellular detoxification capability of GSTs. The degeneration process in the salivary glands during the end of blood-feeding could also be a factor in the decrease of protein expression, as it may cause the release of the GST protein. However, these are just proposed theories, and further studies are warranted to validate these claims. IFAT results also indicated an apparent movement of GSTs from whole cells in the unfed to the apical area of the epithelium in the partially fed to the basal cells in the engorged stage. This apparent movement of GSTs during blood-feeding could indicate the specific location in the midgut where there is exposure to exogenous substances in the blood meal. GST expression could then be an indicator of the amount and location of oxidative stress in the midgut. Among the organs, the midgut showed the highest gene and protein expression; its level of expression could determine the overall trend of GST protein in whole ticks as observed in nymphs and adults.

IFAT results of the fat bodies showed positive fluorescence on the tracheal complex of ticks. This could indicate the role of GST in the detoxification of xenobiotic compounds that may enter ticks through their spiracles. The spiracles and tracheal systems of insects were also observed to be points of entry for insecticides [38]. The presence of GSTs on the organs responsible for the exchange of gases was also observed in the gills of several marine species as well as human lungs [26, 39-41]. In hemocytes, differences in localization were observed. While it is scattered in HLGST, surface localization was observed in HIGST2. Surface localization in mu-class GSTs was also observed in goat sperm [42]. This could be a key feature that needs further study as to how GSTs could play a role in the defense mechanism of the tick's hemocytes and its role in tick immunity.

IFAT of the ovaries showed positive fluorescence in the ovarian wall and into the pedicels. This could be an indication of the mechanism protecting the ovaries of ticks from environmental chemicals that may be acquired through the genital aperture, which is connected to the ovary via the oviduct $[26,43]$. Also, signals in the pedicels of the ovary could reflect its role in the development of oocytes. The presence of numerous mitochondria in the pedicels [44] indicates that they have very high activity, thus consuming lots of oxygen for ATP production. Therefore, pedicels are very metabolically active cells that generate ROS, which in turn could result in the expression of GSTs.

The possibility of the HIGST and HIGST2 antisera to cross react with other GSTs of $H$. longicornis in Western blotting and IFAT remains uncertain since anti-GST sera are known to cross react with other GST proteins with high homology $[2,45]$. Nevertheless, the similarity in the trend in expression and localization indicate how at least 
HIGST and HIGST2, if not all mu-class GSTs of $H$. longicornis, responds to the oxidative stress.

The expression and localization of GSTs in different organs may indicate how ticks use GSTs as protective mechanism to cope with oxidative stress that may vary according to the specific needs of each organ for the enzyme, either as a carrier protein or as being metabolically active [9].

To further investigate the importance of GST and its effects on tick survival during blood-feeding and on reproductive parameters such as engorgement weight, egg weight, and hatching rate, a gene knockdown experiment was performed; however, preliminary results of the gene knockdown experiment (Additional file 5: Table S2) showed no significant differences in the above-mentioned parameters between the GST-knockdown group and the EGFP-knockdown group. In $R$. microplus, no significant differences were observed in terms of tick mortality and oviposition when GST is knocked down [46]. The probable reason is that GSTs could provide functional compensation between members of each family [47], although further studies must be conducted to prove this hypothesis. Vaccination experiments using the HLGST as the antigen, on the other hand, showed a decrease in the engorgement rate of ticks [45]. This could further establish the role of the GSTs during blood-feeding and reproduction, although the exact mechanism should be a subject of future studies.

\section{Conclusions}

In summary, a new GST in the hard tick H. longicornis was identified, and recombinant GSTs were synthesized. Both GSTs of $H$. longicornis were characterized in silico, using various available software applications; in vitro, through studying the enzymatic activity and kinetics; and in vivo, through its gene and protein expression in whole ticks and different organs during blood-feeding and organ localization. The results have shown a positive correlation between the degree and localization of the GSTs with the degree and localization of oxidative stress occurring within the tick during blood-feeding. This close relationship could indicate that GSTs play a possible role in coping with oxidative stress brought about by blood-feeding. The information gathered here could be a tool for designing tick control methods, such as the proper timing of applying acaricides. Since GSTs have also been a target in the design of anti-tick vaccines, the identification of yet another GST that has a lower homology is of importance in better vaccine design. Also, some discrepancies between transcription and expression profiles were found. These results emphasize the notion that GST studies should involve the gene, protein, and enzyme activity; it should also be a multi-faceted study that takes into consideration the capability of this ubiquitous enzyme.

\section{Additional files}

Additional file 1: Figure S1. RT-PCR (a) and Western blotting (b) of knockdown ticks. Ticks were silenced by injecting $1 \mu \mathrm{g}$ of double-stranded RNA (dsRNA) per tick. a Total RNA was extracted from whole 4-day fed GST and EGFP knockdown ticks. CDNA was synthesized and subjected to RT-PCR. PCR products were run on 1.5\% TAE agarose gel and stained with ethidium bromide. Actin was used as loading control. b Protein lysates were extracted from whole 4-day-fed HIGST, HIGST2, HIGST1/2, and EGFP knockdown ticks. Protein lysates were run on 12\% SDS-PAGE gel before being transferred to polyvinylidene difluoride (PVDF) membranes and subjected to Western blotting. Mouse tubulin antiserum was used as control. (PDF 200 kb)

Additional file 2: Figure S2. Nucleotide and deduced amino acid sequences of HIGST (a) and HIGST2 (b) of Haemaphysalis longicornis. Start and stop codons are underlined. Predicted glutathione and substrate binding sites are shaded in black and gray, respectively. The putative polyadenylation signal, AATAAA, is double underlined. (PDF $53 \mathrm{~kb}$ )

Additional file 3: Figure S3. The modeled tertiary structures of HIGST (a) and HIGST2 (b). The model is based on template c1b8xA [48] constructed using PHYRE2 software [49]. Green indicates the N-terminal domain containing the GSH binding site (orange), while red indicates the C-terminal domain containing the substrate binding site (blue). The mu-loop is indicated by bluish green. (PDF $193 \mathrm{~kb}$ )

Additional file 4: Figure S4. Western blotting of adult female ticks during blood-feeding. Protein lysates were extracted from adult female ticks during the different stages of blood-feeding. Protein lysates were run on 12\% SDS-PAGE gel before being transferred to PVDF membranes and subjected to Western blotting. Mouse tubulin antiserum was used as control. Leftmost lane indicates markers for molecular weight. (PDF 253 kb)

Additional file 5: Table S2. Effect of HIGST and/or HIGST2 knockdown on ticks. (DOCX $36 \mathrm{~kb}$ )

Additional file 6: Table S1. $P$ - and $t$-values of GST transcription profiles. (DOCX $40 \mathrm{~kb})$

\section{Abbreviations}

CDNB: 1-chloro-2,4-dinitrobenzene; DCNB: 1,2-dichloro-4-nitrobenzene; dsRNA: double stranded RNA; EGFP: enhanced green fluorescent protein; EST: expressed sequence tags; GSH: glutathione; GST: glutathione S-transferase; HIGST: GST of $H$. longicornis; IFAT: immunofluorescent antibody test; IPTG: isopropyl $\beta$-D-1-thiogalactiopyranoside; LB: Luria-Bertani; ORF: open reading frame; PBS: phosphate buffered saline; pl: isoelectric point; PVDF: polyvinylidene difluoride; rBaGST: recombinant GST of R.(B.) annulatus; ROS: reactive oxygen species; SDS-PAGE: sodium dodecyl sulphate polyacrylamide gel electrophoresis

\section{Acknowledgements} Not applicable.

\section{Funding}

This study was supported by the Japan Society for the Promotion of Science (JSPS) KAKENHI Grant Numbers 15H05264 and 16H05028 and the Japanese Government Ministry of Education, Culture, Sports, Science and Technology Scholarship (Monbukagakusho: MEXT) for doctoral fellowship. The funding bodies have no role in the design of the study and collection, analysis, and interpretation of data and in writing the manuscript.

\section{Availability of data and materials}

The data supporting the conclusions in this study is included in the article and its additional files. The sequence of HLGST2 have been deposited in the GenBank database under the accession number LC169599.

\section{Authors' contributions}

$\mathrm{EPH}$ and $\mathrm{TT}$ designed the experiments. EPH, KK, HM and MRT performed the experiments. EPH, RLG, TH, TM, KF, NT and TT analyzed the data. EPH wrote the manuscript. All authors read and approved the final manuscript. 


\section{Ethics approval and consent to participate}

The care and use of experimental animals in this study were approved by the Animal Care and Use Committee of Kagoshima University (approval numbers VM15055 and VM15056 for the rabbits and mice, respectively).

\section{Consent for publication}

Not applicable.

\section{Competing interests}

The authors declare they have no competing interests.

\section{Publisher's Note}

Springer Nature remains neutral with regard to jurisdictional claims in published maps and institutional affiliations.

\section{Author details \\ 'Laboratory of Infectious Diseases, Joint Faculty of Veterinary Medicine, Kagoshima University, 1-21-24 Korimoto, Kagoshima 890-0056, Japan. ${ }^{2}$ Department of Pathological and Preventive Veterinary Science, The United Graduate School of Veterinary Science, Yamaguchi University, Yoshida, Yamaguchi 753-8515, Japan. ${ }^{3}$ Department of Clinical and Population Health College of Veterinary Medicine and Biomedical Sciences, Cavite State University, 4122 Cavite, Philippines. ${ }^{4}$ Department of Veterinary Paraclinical Sciences, University of the Philippines at Los Baños, College, 3004 Laguna, Philippines. ${ }^{5}$ Department of Parasitology, Kitasato University School of Medicine, Kitasato, Minami, Sagamihara, Kanagawa 252-0374, Japan. 'Laboratory of Parasitology, Joint Faculty of Veterinary Medicine, Kagoshima University, 1-21-24 Korimoto, Kagoshima 890-0056, Japan. ${ }^{7}$ National Agricultural and Food Research Organization, 3-1-5 Kannondai, Tsukuba, Ibaraki 305-0856, Japan.}

Received: 10 October 2017 Accepted: 22 January 2018

\section{Published online: 08 February 2018}

\section{References}

1. Guneidy RA, Shahein YE, AMK A, Zaki ER, Hamed RR. Inhibition of the recombinant cattle tick Rhipicephalus (Boophilus) annulatus glutathione S-transferase. Ticks Tick Borne Dis. 2014;5:528-36.

2. da Silva Vaz Jnr I, Imamura S, Ohashi K, Onuma M. Cloning, expression and partial characterization of a Haemaphysalis longicornis and a Rhipicephalus appendiculatus glutathione S-transferase. Insect Mol Biol. 2004;13:329-35.

3. Zheng H, Li AY, Teel PD, Pérez de León AA, Seshu J, Liu J. Biological and physiological characterization of in vitro blood-feeding in nymph and adult stages of Ornithodoros turicata (Acari: Argasidae). J Insect Physiol. 2015;75:73-9.

4. Galay RL, Umemiya-Shirafuji R, Mochizuki M, Fujisaki K, Tanaka T. Iron metabolism in hard ticks (Acari: Ixodidae): the antidote to their toxic diet. Parasitol Int. 2015;64:182-9.

5. Freitas DRJ, Rosa RM, Moraes J, Campos E, Logullo C, Da Silva Vaz I, Masuda A. Relationship between glutathione S-transferase, catalase, oxygen consumption, lipid peroxidation and oxidative stress in eggs and larvae of Boophilus microplus (Acarina: Ixodidae). Comp Biochem Physiol, Part A Mol Integr Physiol. 2007;146:688-94

6. Hayes JD, Pulford DJ. The glutathione S-transferase supergene family: regulation of GST and the contribution of the isoenzymes to cancer chemoprotection and drug resistance. Crit Rev Biochem Mol Biol. 1995;30:445-600.

7. Tripathy A, Kar SK. Feeding stage, species, body part and sex-specific activity of glutathione S-transferase in mosquito. Trop Biomed. 2015;32:65-75.

8. Perner J, Provazník J, Schrenková J, Urbanová V, Ribeiro JMC, Kopáček P. RNA-seq analyses of the midgut from blood- and serum-fed Ixodes ricinus ticks. Sci Rep. 2016;6:36695

9. Hayes PC, Bouchier IA, Beckett GJ. Glutathione S-transferase in humans in health and disease. Gut. 1991;32:813-8.

10. Maheo K, Antras-Ferry J, Morel F, Langouët S, Guillouzo A. Modulation of glutathione S-transferase subunits $A 2, M 1$, and P1 expression by interleukin-1beta in rat hepatocytes in primary culture. J Biol Chem. 1997;272:16125-32.

11. Coecke S, Vanhaecke T, Foriers A, Phillips IR, Vercruysse A, Shephard EA, Rogiers V. Hormonal regulation of glutathione S-transferase expression in co-cultured adult rat hepatocytes. J Endocrinol. 2000;166:363-71.

12. He H, Chen AC, Davey RB, Ivie GW, George JE. Characterization and molecular cloning of a glutathione S-transferase gene from the tick, Boophilus microplus (Acari: Ixodidae). Insect Biochem Mol Biol. 1999;29:737-43.
13. Rosa de Lima MF, Sanchez Ferreira CA, Joaquim de Freitas DR, Valenzuela JG, Masuda A. Cloning and partial characterization of a Boophilus microplus (Acari: Ixodidae) glutathione S-transferase. Insect Biochem Mol Biol. 2002;32:747-54.

14. Dreher-Lesnick SM, Mulenga A, Simser JA, Azad AF. Differential expression of two glutathione S-transferases identified from the American dog tick, Dermacentor variabilis. Insect Mol Biol. 2006;15:445-53.

15. Shahein YE, El Sayed El-Hakim A, Abouelella AMK, Hamed RR, Allam SA-M, Farid NM. Molecular cloning, expression and characterization of a functional GST mu class from the cattle tick Boophilus annulatus. Vet Parasitol. 2008; 152:116-26.

16. Duscher GG, Galindo RC, Tichy A, Hummel K, Kocan KM, dela Fuente J. Glutathione S-transferase affects permethrin detoxification in the brown dog tick, Rhipicephalus sanguineus. Ticks Tick Borne Dis. 2014;5:225-33.

17. Fujisaki K. Development of acquired resistance precipitating antibody in rabbits experimentally infested with females of Haemaphysalis longicornis (Ixodoidea: Ixodidae). Natl Inst Anim Health Q (Tokyo). 1978;18:27-38.

18. Habig WH, Pabst MJ, Jakoby WB. Glutathione S-transferases. The first enzymatic step in mercapturic acid formation. J Biol Chem. 1974;249:7130-9.

19. Aung KM, Boldbaatar D, Liao M, Umemiya-Shirafuji R, Nakao S, Matsuoka T, et al. Identification and characterization of class B scavenger receptor CD36 from the hard tick, Haemaphysalis longicornis. Parasitol Res. 2011;108:273-85.

20. Umemiya-Shirafuji R, Tanaka T, Boldbaatar D, Tanaka T, Fujisaki K. Akt is an essential player in regulating cell/organ growth at the adult stage in the hard tick Haemaphysalis longicornis. Insect Biochem Mol Biol. 2012;42:164-73.

21. Galay RL, Aung KM, Umemiya-Shirafuji R, Maeda H, Matsuo T, Kawaguchi $H$, et al. Multiple ferritins are vital to successful blood-feeding and reproduction of the hard tick Haemaphysalis longicornis. J Exp Biol. 2013; 216(Pt 10):1905-15.

22. Bathige SDNK, Umasuthan N, Saranya Revathy K, Lee Y, Kim S, Cho MY, et al. A mu class glutathione S-transferase from Manila clam Ruditapes

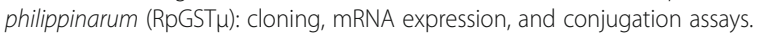
Comp Biochem Physiol C Toxicol Pharmacol. 2014;162:85-95.

23. Reddy BPN, Prasad GBKS, Raghavendra K. In silico analysis of glutathione S-transferase supergene family revealed hitherto unreported insect specific $\delta$ - and $\varepsilon$-GSTs and mammalian specific $\mu$-GSTs in Ixodes scapularis (Acari: Ixodidae). Comput Biol Chem. 2011:35:114-20.

24. da Silva Vaz I, Torino Lermen T, Michelon A, Sanchez Ferreira CA, Joaquim de Freitas DR, Termignoni C, Masuda A. Effect of acaricides on the activity of a Boophilus microplus glutathione S-transferase. Vet Parasitol. 2004;1 19:237-45.

25. Kingsley LJ, Lill MA. Substrate tunnels in enzymes: structure-function relationships and computational methodology. Proteins. 2015;83:599-611.

26. Clark AG. The comparative enzymology of the glutathione S-transferases from non-vertebrate organisms. Comp Biochem Physiol, B. 1989;92:419-46.

27. Daniel V. Glutathione S-transferases: gene structure and regulation of expression. Crit Rev Biochem Mol Biol. 1993;28:173-207.

28. Rudenko N, Golovchenko M, Edwards MJ, Grubhoffer L. Differential expression of Ixodes ricinus tick genes induced by blood-feeding or Borrelia burgdorferi infection. J Med Entomol. 2005;42:36-41.

29. Sonenshine DE, Anderson JM. Mouthparts and digestive system: anatomy and molecular biology of feeding and digestion. In: Sonenshine DE, Roe MR, editors. Biology of Ticks. New York: Oxford University Press; 2014. p. 122-62

30. Perner J, Sobotka R, Sima R, Konvickova J, Sojka D, de Oliveira PL, et al. Acquisition of exogenous haem is essential for tick reproduction. Elife. 2016; 5:e12318

31. Toh SQ, Glanfield A, Gobert GN, Jones MK. Heme and blood-feeding parasites: friends or foes? Parasit Vectors. 2010;3:108.

32. Tirloni L, Islam MS, Kim TK, Diedrich JK, Yates JR, Pinto AFM, et al. Saliva from nymph and adult females of Haemaphysalis longicornis: a proteomic study. Parasit Vectors. 2015:8:338

33. Kim TK, Tirloni L, AFM P, Moresco J, Yates JR, da Silva Vaz I, Mulenga A. Ixodes scapularis tick saliva proteins sequentially secreted every $24 \mathrm{~h}$ during blood-feeding. PLoS Negl Trop Dis. 2016;10:e0004323.

34. Radulović ŽM, Kim TK, Porter LM, Sze S-H, Lewis L, Mulenga A. A 24-48 h fed Amblyomma americanum tick saliva immuno-proteome. BMC Genomics. 2014;15:518

35. Mukherjee SB, Aravinda S, Gopalakrishnan B, Nagpal S, Salunke DM, Shaha C. Secretion of glutathione S-transferase isoforms in the seminiferous tubular fluid, tissue distribution and sex steroid binding by rat GSTM1. Biochem J. 1999;340(Pt 1):309-20.

36. Howie AF, Hayes PC, Bouchier IA, Hayes JD, Beckett GJ. Glutathione S-transferase in human bile. Clin Chim Acta. 1989;184:269-78. 
37. Kura T, Takahashi Y, Takayama T, Ban N, Saito T, Kuga T, Niitsu Y. Glutathione S-transferase-pi is secreted as a monomer into human plasma by platelets and tumor cells. Biochim Biophys Acta. 1996;1292:317-23.

38. Stadler T, Buteler M. Modes of entry of petroleum distilled spray-oils into insects: a review. Bull Insectology. 2009;62(2):169-77.

39. Tate $L G$, Herf DA. Characterization of glutathione S-transferase activity in tissues of the blue crab, Callinectes sapidus. Comp Biochem Physiol C. 1978; 61:165-9.

40. James MO, Bowen ER, Dansette PM, Bend JR. Epoxide hydrase and glutathione S-transferase activities with selected alkene and arene oxides in several marine species. Chem Biol Interact. 1979;25:321-44.

41. Oesch F, Schmassmann H, Ohnhaus E, Althaus U, Lorenz J. Monooxygenase, epoxide hydrolase, and glutathione-S-transferase activities in human lung. Variation between groups of bronchogenic carcinoma and non-cancer patients and interindividual differences. Carcinogenesis. 1980;1:827-35.

42. Gopalakrishnan B, Aravinda S, Pawshe CH, Totey SM, Nagpal S, Salunke DM, Shaha C. Studies on glutathione S-transferases important for sperm function: evidence of catalytic activity-independent functions. Biochem J. 1998;329(Pt 2):231-41.

43. Matsuo T, Okura N, Kakuda H, Yano Y. Reproduction in a Metastriata tick, Haemaphysalis longicornis (Acari: Ixodidae). J Acarol Soc Jpn. 2013;22:1-23.

44. de Oliveira PR, Mathias MIC, Bechara GH. Vitellogenesis in the tick Amblyomma triste (Koch, 1844) (Acari: Ixodidae) role for pedicel cells. Vet Parasitol. 2007;143:134-9.

45. Parizi LF, Utiumi KU, Imamura S, Onuma M, Ohashi K, Masuda A, da Silva Vaz I. Cross-immunity with Haemaphysalis longicornis glutathione S-transferase reduces an experimental Rhipicephalus (Boophilus) microplus infestation. Exp Parasitol. 2011;127:113-8.

46. Almazán C, Lagunes R, Villar M, Canales M, Rosario-Cruz R, Jongejan F, dela Fuente J. Identification and characterization of Rhipicephalus (Boophilus) microplus candidate protective antigens for the control of cattle tick infestations. Parasitol Res. 2010;106:471-9.

47. Bhattacharjee P, Paul S, Banerjee M, Patra D, Banerjee P, Ghoshal N, et al. Functional compensation of glutathione S-transferase M1 (GSTM1) null by another GST superfamily member, GSTM2. Sci Rep. 2013:3:2704.

48. Tang L, Guo B, van Wijnen AJ, Lian JB, Stein JL, Stein GS, Zhou GW. Preliminary crystallographic study of glutathione S-transferase fused with the nuclear matrix targeting signal of the transcription factor AML-1/CBFalpha2. J Struct Biol. 1998;123:83-5.

49. Kelley LA, Sternberg MJE. Protein structure prediction on the Web: a case study using the Phyre server. Nat Protoc. 2009;4:363-71.

\section{Submit your next manuscript to BioMed Central and we will help you at every step:}

- We accept pre-submission inquiries

- Our selector tool helps you to find the most relevant journal

- We provide round the clock customer support

- Convenient online submission

- Thorough peer review

- Inclusion in PubMed and all major indexing services

- Maximum visibility for your research

Submit your manuscript at www.biomedcentral.com/submit 